\title{
Observational case series: six neurosurgical patients with septic shock demonstrating clinical improvement after a combination of standard care and blood purification
}

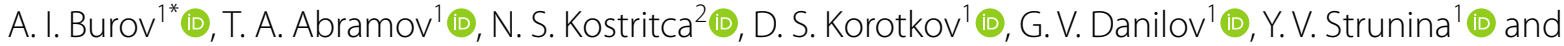 \\ I. A. Savin ${ }^{1}$ (D)
}

\begin{abstract}
Background: For patients with primary brain injury, septic shock is especially dangerous due to the possibility of secondary cerebral damage. The key factor of sepsis-associated brain injury is inflammatory mediators, pathogen and damage-associated molecular patterns (PAMPs, DAMPs) release. Theoretically, blood purification may be beneficial for patients with primary brain injury due to its possibility for fast removal of inflammatory mediators.

Case presentation: We report on six post-neurosurgery septic shock patients treated with combined blood purification (CBP), which included CRRT with high adsorption capacity membrane in combination with CytoSorb adsorber. Clinical improvement in the course of CBP was registered in all patients. Three patients had a stable clinical improvement; the other three patients had only a transient improvement due to underlying neurological and cardiac deficits aggravation. We observed septic shock reversal in four patients. The key observations of the case series are a significant decrease in MOF severity (measured by SOFA score) and in catecholamine need (not statistically significant). By the end of CBP we observed a significant decrease in blood lactate, PCT and IL-6 levels. Two patients demonstrated level of consciousness increase in the setting of CBP therapy measured by GCS and FOUR score.
\end{abstract}

Conclusion: This case series demonstrates that CBP therapy may have a role for septic shock patients with primary brain injury.

Keywords: Septic shock, Blood purification, Hemoadsorption, Inflammatory mediators adsorber, High adsorption capacity membrane, Continuous renal replacement therapy

\section{Introduction}

It has been described that septic shock is associated with a higher risk of mortality in ICU patients [1]. It is important to be mindful of septic shock being the driver of the secondary brain damage in neurosurgical patients. The

\footnotetext{
*Correspondence: aleksander.bour@mail.ru

${ }^{1}$ Federal State Autonomous Institution N. N. Burdenko National Medical Research Center of Neurosurgery of the Ministry of Health of the Russian Federation, Moscow, Russian Federation

Full list of author information is available at the end of the article
}

mechanisms of pathogen and damage-associated molecular patterns (PAMPs, DAMPs) based immunity activation, cytokine release-driven endothelial damage and subsequent hematoencephalic barrier function affliction are well described [2]. The described phenomena lead to vasogenic brain edema development $[3,4]$. Cerebral perfusion decreases in septic shock, being the secondary brain injury driver, is especially deleterious to patients with pre-existing cerebral blood flow autoregulation disturbances [2]. 


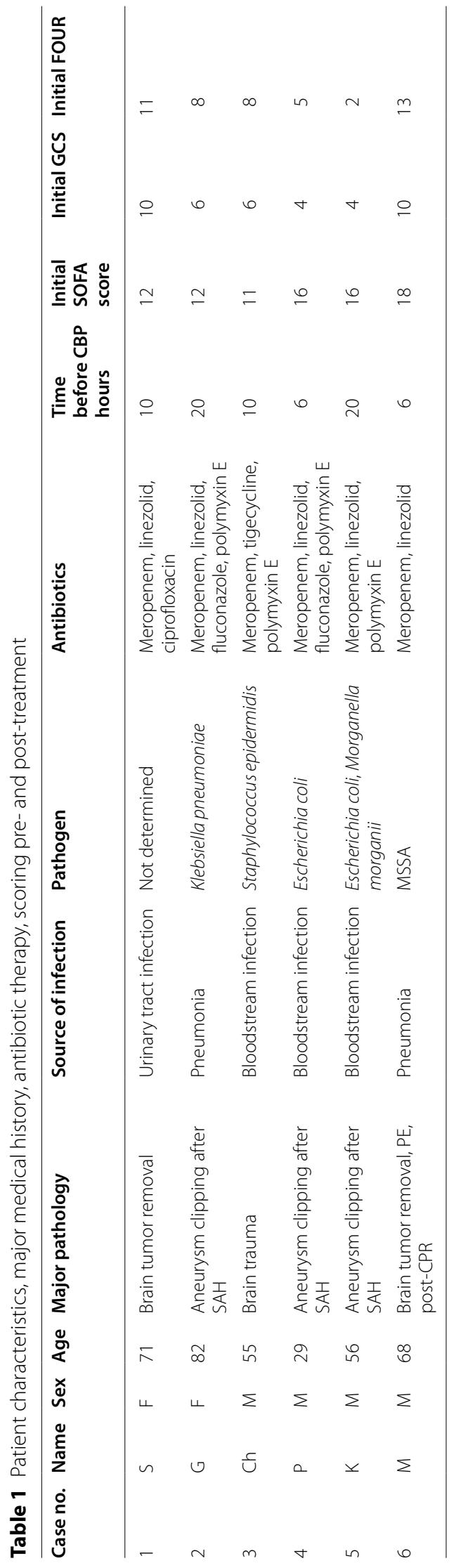


Even though the benefits of combined antibacterial therapy in septic shock have been demonstrated [1], in some cases its timely use does not entail fast hemodynamic stabilization and multiple organ failure (MOF) regress. For patients not responding to standard therapy, blood purification techniques may potentially be effective. The most important reason for blood purification in neurosurgical patients is the maximally fast PAMPs and DAMPs elimination, allowing to minimize secondary brain damage [3].

The use of CRRT with standard membranes in continuous veno-venous hemofiltration mode was not associated with mortality decrease [5]. Apart from that, conventional CRRT has not proved effective in terms of cytokine elimination, whereas cytokines are considered key factors of hemodynamic instability progression and MOF development [5]. Nowadays there exist other adjuvant methods, providing for fast and effective cytokine, PAMPs and DAMPs elimination from systemic blood flow: increased adsorption capacity membranes, inflammatory mediators adsorbers and lipopolysaccharide columns [6-8]. Several studies on CytoSorb (Cytosorbents, USA) demonstrated effective elimination of substances, described above [9-12].

To our knowledge, publications on the use of adjuvant blood purification methods in neurosurgical patients with septic shock are scarce. This case series describes the treatment of six patients after neurosurgical interventions who developed septic shock and received adjuvant therapy with combined blood purification.

\section{Methods}

We report on six adult post-neurosurgery septic shock patients with median age of 62 [55-71] $(\mathrm{CH}, \mathrm{G}, \mathrm{K}, \mathrm{M}, \mathrm{P}$, $\mathrm{S})$. In all of them septic shock was diagnosed according to Sepsis-3 criteria [2]. Patient characteristics are presented in Table 1. All patients received standard therapy according to Surviving Sepsis Campaign guidelines [1]. Antibacterial therapy was started within $1 \mathrm{~h}$ of septic shock diagnosis. Dosages of antibacterial drugs were used in accordance with the recommendations for patients on CRRT; therapeutic drug monitoring was not available at our facility at the time. All patients were non-responders to standard therapy within 6 or more hours of septic shock: vasopressor demand continued to rise (norepinephrine $(\mathrm{NE})>0.1 \mu \mathrm{g} / \mathrm{kg} / \mathrm{min}$ or a combination of vasopressors) and MOF was progressing (SOFA score $\geq 11$ ). The median SOFA score was 14 [12;16]. All patients had AKI (KDIGO I-III).

CBP consisted of CRRT and inflammatory mediators' adsorber (CytoSorb) in all patients. CBP therapy was started within $10 \mathrm{~h}$ after septic shock diagnosis in 4 patients and within $20 \mathrm{~h}$ in the other 2 patients.
CRRT was performed in CVVHDF mode using Prismaflex (Gambro Medical) with AN69ST set in 5 patients $(\mathrm{CH}, \mathrm{G}, \mathrm{M}, \mathrm{P}, \mathrm{S})$ and lipopolysaccharide elimination membrane (oXiris (Baxter International Inc.) in 1 patient (K) who had Endotoxin Activity Assay (EAA) test 0.67. CBP was performed with CytoSorb adsorber in all our patients. CytoSorb was placed in the post-filter position for $24 \mathrm{~h}$ for all patients. Blood flow rate was $150-200 \mathrm{ml} /$ min. Anticoagulation was performed with heparin (5-15 $\mathrm{U} / \mathrm{kg} / \mathrm{h}$ ) in 2 patients, monitored by aPTT with target level 1.5-2 times higher than the normal; citrate in 3 patients; 1 patient was not anticoagulated due to severe thrombocytopenia. The overall CBP therapy duration was $24 \mathrm{~h}$ for all patients. In four patients, CRRT and inflammatory mediators adsorption were started simultaneously in combination. Patient $\mathrm{K}$ received CRRT with AN69 membrane in CVVHDF mode for $20 \mathrm{~h}$, patient $\mathrm{M}-$ for $72 \mathrm{~h}$ before CytoSorb installation.

To assess CBP effects, vasopressor requirements, SOFA score and lactate levels were recorded in all patients (Table 2). Shock reversal was recorded, defined as vasopressor requirement decrease and lactate level normalization. Procalcitonin (PCT), C-reactive protein (CRP) and IL-6 levels were evaluated (Table 3). Glasgow Coma Scale (GCS) and FOUR score were calculated to assess CBP effects on the consciousness level. We assessed outcome in terms of days on CRRT, 7-, 28-day and hospital mortality (Table 4).

Statistical data analysis was carried out using the $\mathrm{R}$ environment (version 3.6.1) in IDE $\mathrm{R}$ Studio (version 1.2.1335). Statistical hypotheses about the difference in the distribution of quantitative variables in the samples were tested using the nonparametric Wilcoxon test. The results of testing hypotheses were considered statistically significant at a level of $p<0.05$.

\section{Results}

Clinical improvement during the course of CBP was registered in all our patients. 3 patients $(\mathrm{CH}, \mathrm{G}, \mathrm{S})$ had a stable clinical improvement (MOF regress and lactate level decrease); the other 3 patients (P, K, M) had a transient improvement (vasopressor dose decrease (P, K), SOFA score and lactate level reduction (P, K, M)). We observed septic shock reversal in four patients $(\mathrm{CH}, \mathrm{G}, \mathrm{K}, \mathrm{S})$. For those with transient improvement, it was conditioned by their malignant edema and following cerebral herniation in the setting of the underlying condition $(\mathrm{P}, \mathrm{K})$ or cardiac insufficiency progress after massive pulmonary embolism (M).

Median NE demand for all patients reduced from a median of $0.89[0.73 ; 1.51] \mu \mathrm{g} / \mathrm{kg} / \mathrm{min}$ before CBP to 0.19 $[0.11 ; 1.29] \mu \mathrm{g} / \mathrm{kg} / \mathrm{min}$ in $24 \mathrm{~h}$ and to $0.16[0 ; 1] \mu \mathrm{g} / \mathrm{kg} / \mathrm{min}$ in $72 \mathrm{~h}$ after CBP initiation (not statistically significant) 


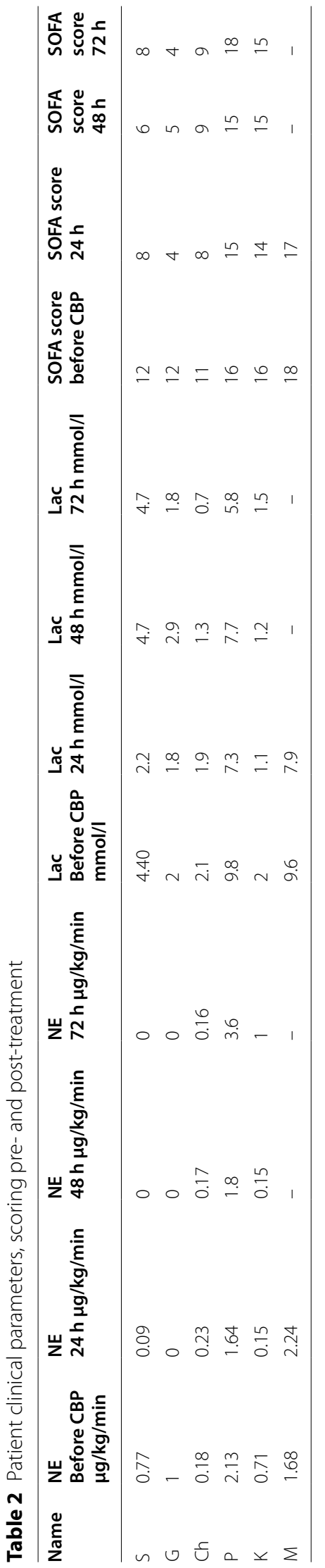


Table 3 Inflammatory mediator's levels pre- and post-treatment

\begin{tabular}{|c|c|c|c|c|c|c|c|c|c|c|c|c|c|c|}
\hline \multirow[t]{2}{*}{ Name } & \multirow[t]{2}{*}{$\begin{array}{l}\text { PCT } \\
\text { Before CBP } \mathrm{ng} / \mathrm{ml}\end{array}$} & \multirow[t]{2}{*}{$\begin{array}{l}\text { PCT } \\
6 \mathrm{~h} \\
\mathrm{ng} / \mathrm{ml}\end{array}$} & \multirow[t]{2}{*}{$\begin{array}{l}\mathrm{PCT} \\
12 \mathrm{~h} \\
\mathrm{ng} / \mathrm{ml}\end{array}$} & \multirow[t]{2}{*}{$\begin{array}{l}\text { PCT } \\
24 \mathrm{~h} \\
\mathrm{ng} / \mathrm{ml}\end{array}$} & \multicolumn{2}{|c|}{$\begin{array}{l}\text { Cytokines } \\
\text { Before CBP } \\
\mathrm{pg} / \mathrm{ml}\end{array}$} & \multicolumn{2}{|c|}{$\begin{array}{l}\text { Cytokines } \\
6 \mathrm{~h} \mathrm{pg} / \mathrm{ml}\end{array}$} & \multicolumn{2}{|c|}{$\begin{array}{l}\text { Cytokines } \\
24 \mathrm{~h} \mathrm{pg} / \mathrm{ml}\end{array}$} & \multirow[t]{2}{*}{$\begin{array}{l}\text { CRP } \\
\text { Before CBP mg/l }\end{array}$} & \multirow[t]{2}{*}{$\begin{array}{l}\text { CRP } \\
24 \mathrm{~h} \\
\mathrm{mg} / \mathrm{l}\end{array}$} & \multirow[t]{2}{*}{$\begin{array}{l}\text { CRP } \\
48 \mathrm{~h} \\
\mathrm{mg} / \mathrm{l}\end{array}$} & \multirow[t]{2}{*}{$\begin{array}{l}\text { CRP } \\
72 \mathrm{~h} \\
\mathrm{mg} / \mathrm{l}\end{array}$} \\
\hline & & & & & IL-6 & IL-10 & IL-6 & IL-10 & IL-6 & IL-10 & & & & \\
\hline$S$ & $>200$ & $>200$ & 81.74 & 86.62 & 3797 & 585 & 464 & 31 & 85 & 21.1 & 34.7 & 23.7 & 35.4 & 28.2 \\
\hline G & 18.13 & 4.15 & 4.46 & 4.43 & 194 & 9,5 & 34 & 5.0 & 76 & 5.7 & 71.6 & 48.6 & 57.2 & 48.8 \\
\hline Ch & $>200$ & 46.72 & 34.59 & 22.52 & 56 & $<5.0$ & 34 & $<5.0$ & 24 & $<5.0$ & 182 & 181.5 & 102.2 & 69.8 \\
\hline P & 139.53 & 57.65 & 66,53 & 78.29 & 32,280 & 1030 & 9142 & 80.6 & 6352 & 104 & 215.8 & 250 & 254.4 & 298.1 \\
\hline K & 56 & 37.8 & 32 & 29.34 & 141 & 71.8 & 19.46 & 19.3 & 20.98 & 9.8 & 257.3 & 167.2 & 131.8 & 68 \\
\hline M & 5.32 & 1.79 & 1.65 & 1.43 & 1598 & 133 & 592 & 50.1 & 344.6 & 14.8 & 95.1 & 129.7 & - & - \\
\hline
\end{tabular}

(Fig. 1). Hemodynamic stabilization was accompanied by a decrease in blood lactate from a median of 3.25 [2.03;8.3] $\mathrm{mmol} / \mathrm{l}$ before CBP to $2.05[1.83 ; 6.03] \mathrm{mmol} / \mathrm{l}$ in $24 \mathrm{~h}$ $(p=0.031)$ and to $1.8[1.5 ; 4.7] \mathrm{mmol} / \mathrm{l}$ in $72 \mathrm{~h}$ after CBP initiation (not statistically significant) (Fig. 2). Two patients (G, S) demonstrated quick vasopressor demand reduction; vasopressor support could be discontinued for them $48 \mathrm{~h}$ after CBP initiation.

Mean SOFA score decreased from a median of 14 [12;16] before CBP to $11[8 ; 14.75]$ in $24 \mathrm{~h}(p=0.036)$ and to 9 $[8 ; 15]$ in $72 \mathrm{~h}$ after CBP initiation (not statistically significant) (Fig. 3). SOFA score changes were conditioned by renal $(\mathrm{G}, \mathrm{CH}, \mathrm{S}, \mathrm{P}, \mathrm{K})$, cardiovascular $(\mathrm{G}, \mathrm{S})$ and hepatic $(\mathrm{CH}, \mathrm{K})$ insufficiency regress, lung function restoration $(\mathrm{G}$, $\mathrm{M}, \mathrm{S}$ ) and consciousness level rise (G, S). At the same time, in patients $\mathrm{G}$ and $\mathrm{S}$ thrombocytopenia progressed due to disseminated intravascular coagulation (DIC) development in the setting of septic shock (platelet concentration decreased from 179 to $70^{*} 10^{9} / \mathrm{l}(\mathrm{G})$ and from 80 to $21^{*} 10^{9} / \mathrm{l}$ (S) in $24 \mathrm{~h}$ after CBP initiation); this conditioned some moderate SOFA score increase.

We registered fast statistically significant decrease of PCT and IL-6 levels: PCT reduced more than $66 \%$ in $12 \mathrm{~h}$ and more than $74 \%$ in $24 \mathrm{~h}$ after CBP initiation (Fig. 4); IL-6-more than $71 \%$ in $6 \mathrm{~h}$ and $95 \%$ in $24 \mathrm{~h}$ after CBP initiation (Fig. 5).

Median CRP level decreased from 138.55 [77.48;207.35] $\mathrm{mg} / \mathrm{l}$ before CBP to 102.2 [57.2;131.8] $\mathrm{mg} / \mathrm{l}$ in $48 \mathrm{~h}$ and to 68 [48.8;69.8] $\mathrm{mg} / \mathrm{l}$ in $72 \mathrm{~h}$ after CBP initiation (both-not statistically significant) (Fig. 6).

Two patients demonstrated improved level of consciousness during CBP therapy: S (GCS from 10 to 11; FOUR score from 11 to 13) and G (GCS from 6 to 9; FOUR score from 8 to 10$)$.

There were no adverse events during the procedure.

\section{Discussion}

Combined blood purification is becoming widely used in contemporary ICUs, but there are very few reports on the use of any blood purification methods in neurosurgical ICU [13].

In this case series, six patients with septic shock (median SOFA score 14) and AKI were treated with CBP therapy. The treatment was associated with a significant reduction of SOFA score, lactate and PCT levels at $24 \mathrm{~h}$ after CBP initiation. $83 \%$ of patients (5/6) demonstrated vasopressor demand decrease within 6-48 h of CBP start. Shock reversal was observed in four patients. Stable clinical improvement was noted in 50\% (3 out of 6 ) of patients already within $24 \mathrm{~h}$ and then continued at $72 \mathrm{~h}$ after CBP initiation. We observed similar data in other publications concerning general ICU patients [14-16]. One patient (G) with stable clinical improvement died 25 days after CBP start due to cerebral hemorrhage; however, treatment of septic shock was successful. Other two patients with stable clinical improvement were discharged to the rehabilitation center.

The reason for only transient improvement of the other $50 \%$ of patients is related to their underlying condition (brain herniation and brain death (P, K) or massive pulmonary embolism (M)). The improvement was evident, though, and one of these patients even had a shock reversal. We think that the high early mortality $(50 \%)$ in our case series is explained primarily by the specifics of severe cerebral injury. In addition, MOF severity by SOFA score in our patients was higher than in most studies on septic shock.

Thrombocytopenia progress in $\mathrm{G}$ and $\mathrm{S}$ was conditioned by DIC development in the setting of septic shock. In our opinion, this phenomenon was not the adverse effect of the CBP treatment, but rather a characteristic 
Table 4 Patient scoring pre- and post-treatment and patient outcome

\begin{tabular}{lccccccccccc}
\hline Name & Initial GCS & $\begin{array}{l}\text { GCS } \\
\mathbf{2 4} \mathbf{h}\end{array}$ & $\begin{array}{l}\text { GCS } \\
\mathbf{7 2} \mathbf{h}\end{array}$ & $\begin{array}{l}\text { Initial } \\
\text { FOUR }\end{array}$ & $\begin{array}{l}\text { FOUR } \\
\mathbf{2 4} \mathbf{h}\end{array}$ & $\begin{array}{l}\text { FOUR } \\
\mathbf{7 2} \mathbf{h}\end{array}$ & $\begin{array}{l}\text { CRRT days } \\
\text { Shock reversal }\end{array}$ & $\begin{array}{l}\text { 7-day } \\
\text { mortality }\end{array}$ & $\begin{array}{l}\text { 28-day } \\
\text { mortality }\end{array}$ & $\begin{array}{l}\text { Hospital } \\
\text { mortality }\end{array}$ \\
\hline S & 10 & 10 & 11 & 11 & 11 & 13 & 0 & Yes & No & No & No \\
G & 6 & 6 & 9 & 8 & 8 & 10 & 0 & Yes & No & Yes & Yes \\
Ch & 6 & 6 & 6 & 8 & 8 & 8 & 1 & Yes & No & No & No \\
P & 4 & 4 & 3 & 5 & 5 & 0 & 2 & No & Yes & Yes & Yes \\
K & 4 & 4 & 3 & 2 & 2 & 0 & 2 & Yes & Yes & Yes & Yes \\
M & 10 & 10 & - & 13 & 13 & - & 0 & No & Yes & Yes & Yes \\
\hline
\end{tabular}

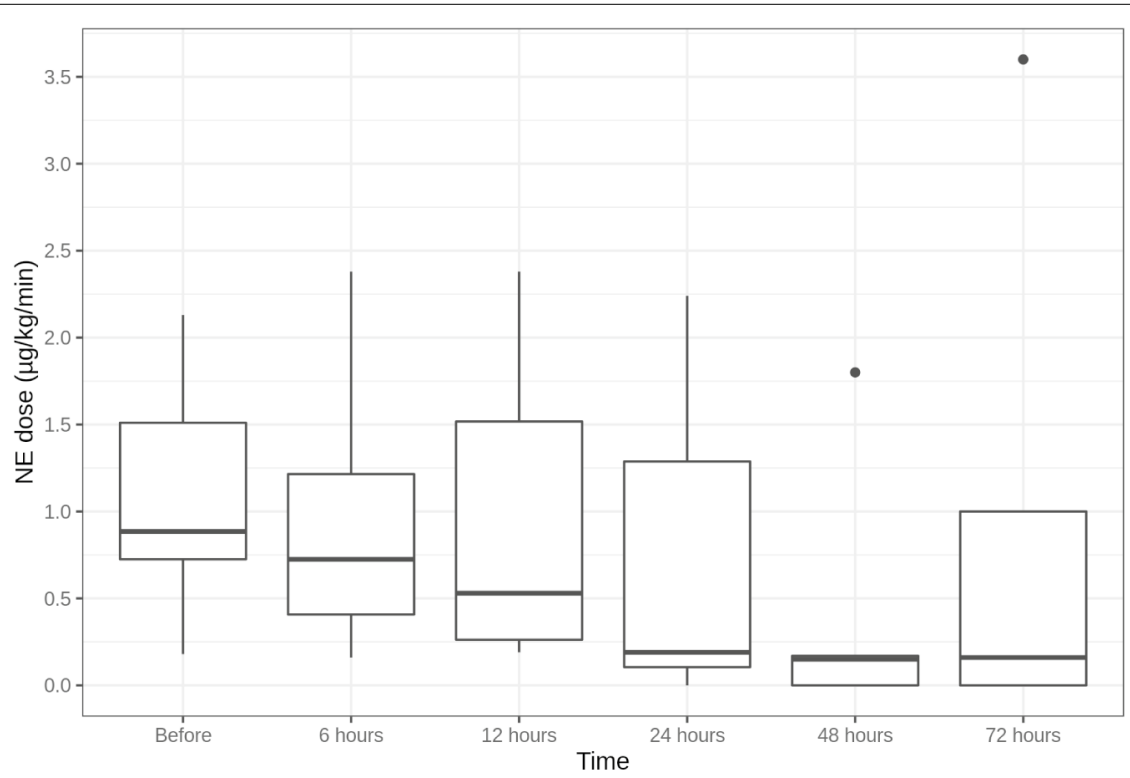

Fig. $1 \mathrm{NE}$ dose dynamics ( $\mu \mathrm{g} / \mathrm{kg} / \mathrm{min})$

feature of a typical DIC syndrome progression, when platelet concentration dramatically decreases $[6,17]$.

Studies show that the degree of hypercytokinemia correlates with mortality [7], and that the highest mortality rate is observed in patients with simultaneously increased pro- and anti-inflammatory cytokine levels [8]. In our case series, three patients $(\mathrm{M}, \mathrm{P}, \mathrm{S})$ had excessive levels of both types of cytokines parallel to high vasopressor demand, lactate level and SOFA score. Despite their severe condition, we observed clinical improvement in the course of CBP (transient or stable).

Cytokine levels dynamics characterize both septic shock treatment and CBP effectiveness [11]. Gruda et al. stated that $5 \mathrm{~h}$ of cytokine adsorption could reduce IL-6 level by $91 \pm 3.0 \%$ [10]. In the described case series, cytokines elimination was observed during the whole procedure $(24 \mathrm{~h})$ with the maximum effect during the first 6-12 h. Cytokine clearance was more prominent in patients with extremely high $(>1000 \mathrm{pcg} / \mathrm{ml})$ initial IL-6 levels (M, P, S)-more than $78 \%$ in $24 \mathrm{~h}$. Very similar data on direct proportion of cytokines elimination to their initial concentrations were described in other publications [18].

Of special interest is the PCT in the setting of antibacterial therapy and its dynamics during blood purification. Substantial PCT reduction could indicate effective antibacterial therapy and adequate infection control in general; PCT dynamics also can be used as a prognostic marker. According to the literature, a twofold decrease in the PCT level in blood within 5 days is associated with a favorable outcome in patients with sepsis. The mortality rate of patients with a $50 \%$ or more decrease in PCT was $29 \%$, and out of those with a decrease of less than $50 \%$ the mortality reached $86 \%$ [19]. We observed a significantly greater decrease in the PCT level during the blood purification procedure. It has to be noted that PCT is eliminated by the adsorber and some other blood purification methods [20]. PCT reduced significantly in all patients at 6-12 $\mathrm{h}$ and then continued to decrease at $18 \mathrm{~h}$ of CBP at lower speeds 


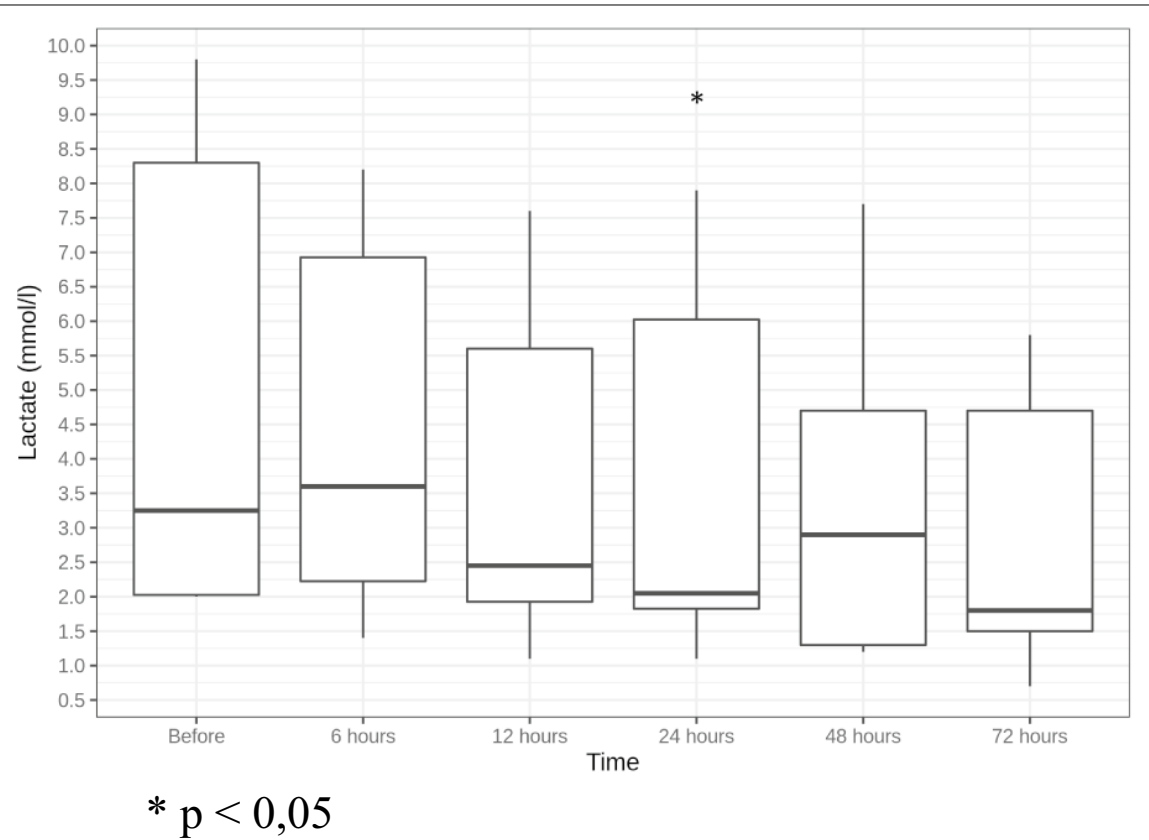

Fig. 2 Lactate level dynamics $(\mathrm{mmol} / \mathrm{l}) .{ }^{*} p<0.05$

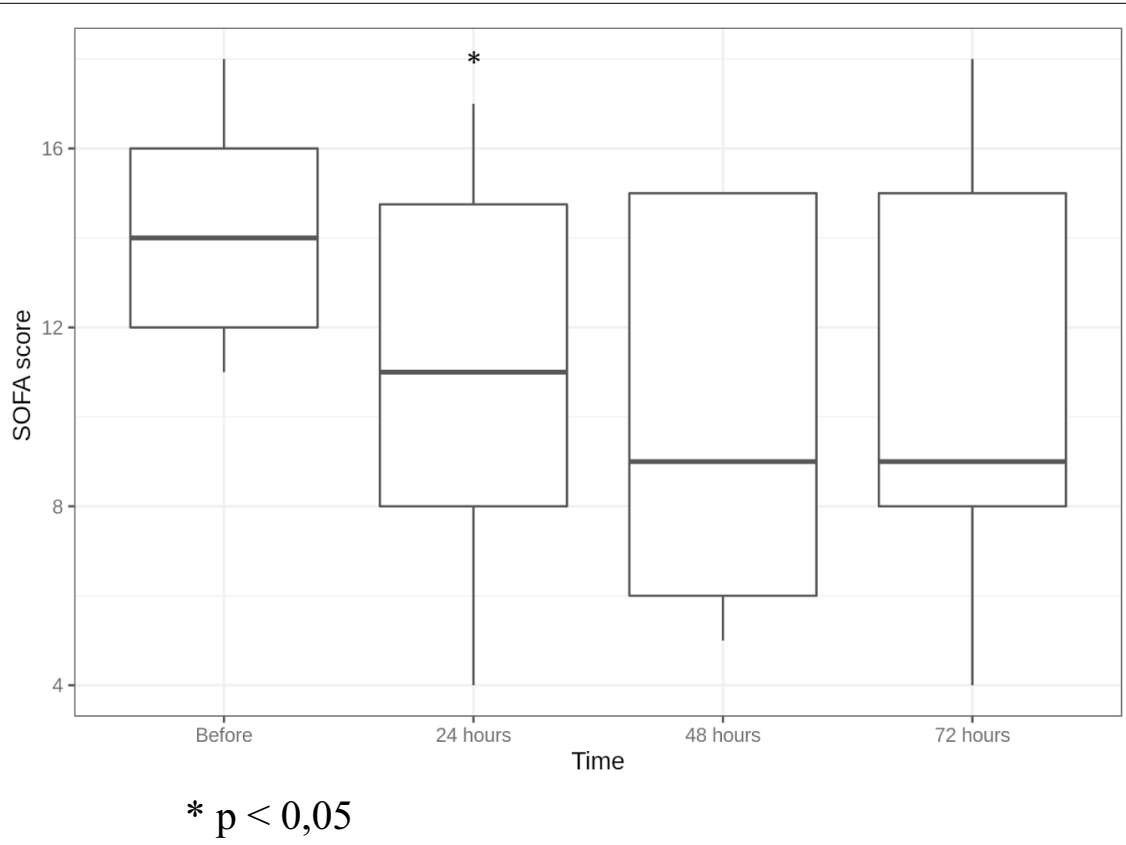

Fig. 3 SOFA score dynamics. ${ }^{*} p<0.05$

(except for Patient P). The most pronounced PCT elimination (about twofold or more) took place within the first $6 \mathrm{~h}$. After CBP was discontinued, two patients (G, S) demonstrated a small transient PCT increase, then again a decrease at $72 \mathrm{~h}$. In our opinion, unusual PCT dynamics in patient $\mathrm{P}$ (the concentration decreased by $59 \%$ at $6 \mathrm{~h}$, and started to rise at $12 \mathrm{~h}$, the increase continued until patient's death) could be explained by underperformance of antibacterial therapy or non-controlled infection source presence. 


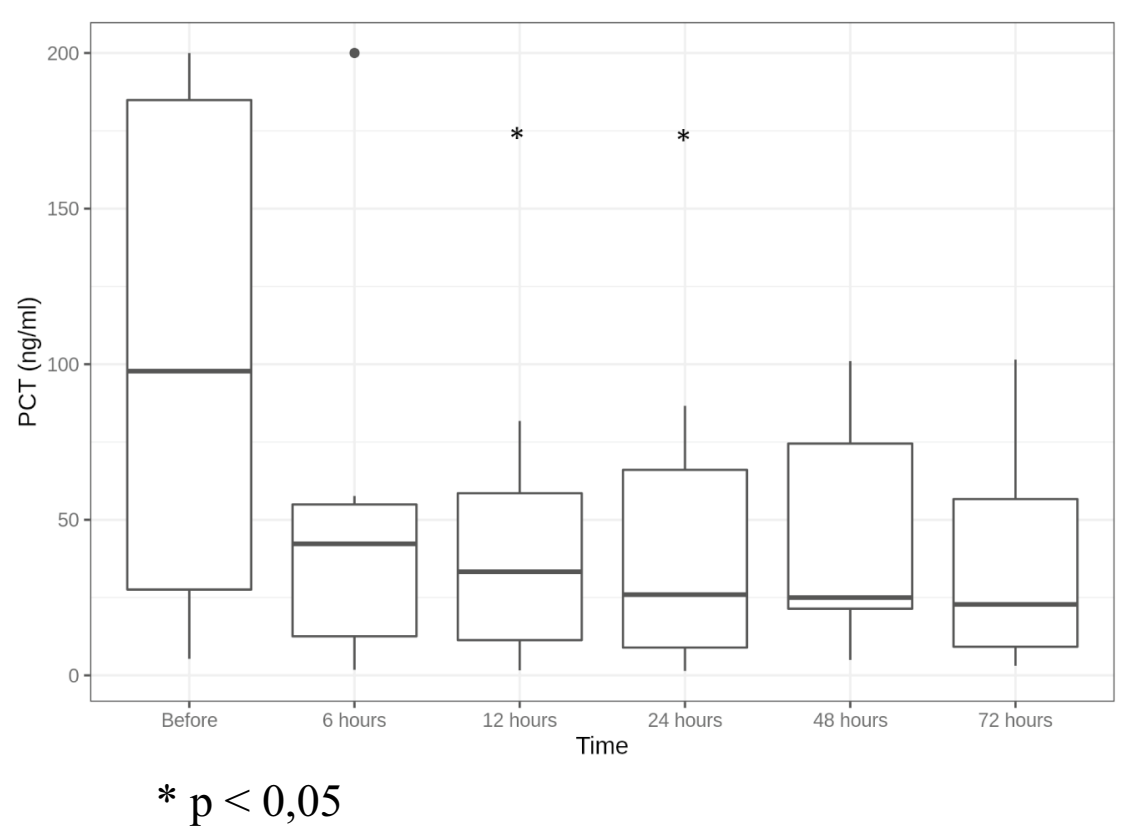

Fig. 4 PCT level dynamics (ng/ml). ${ }^{*} p<0.05$

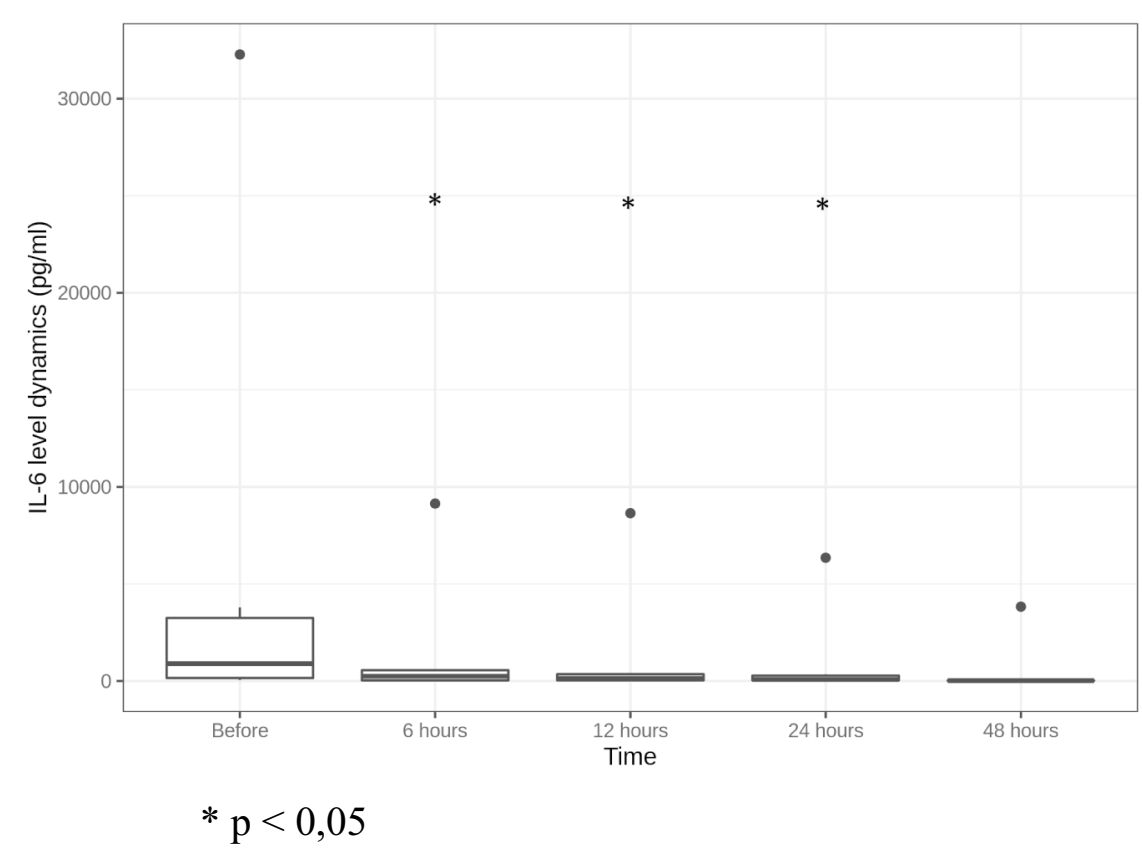

Fig. 5 IL-6 level dynamics $(\mathrm{pg} / \mathrm{ml}){ }^{*} p<0.05$

Matsui et al. reported that CRRT use in patients with stroke had a beneficial effect on the consciousness level [13]. Based on the improved level of consciousness (GCS and FOUR scale increase) parallel to shock reversal in two patients (G, S), we hypothesize on the positive
CBP influence on the neurological status in comparison with the standard septic shock therapy. We assessed the change in neurological status primarily using the FOUR scale, taking into account its advantages in patients on mechanical ventilation. The FOUR score evaluation made 


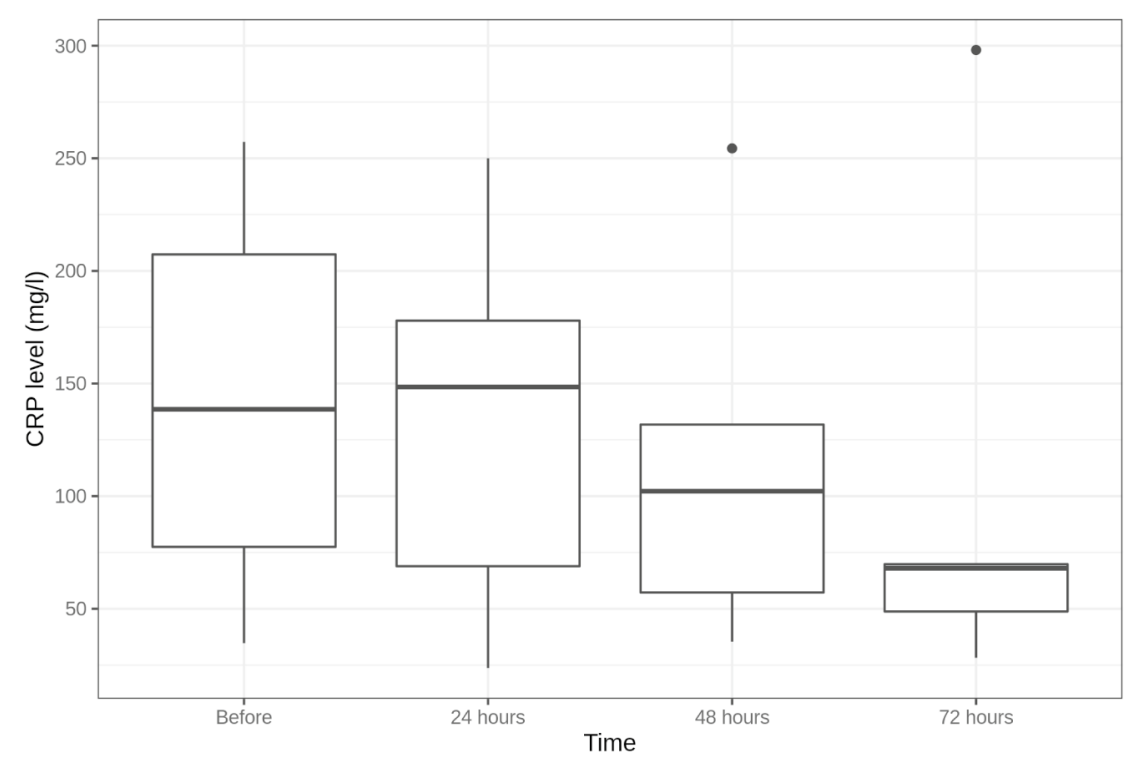

Fig. 6 CRP level dynamics (mg/l)

it possible to assess the changes in neurological status accurately and quickly, which was especially important for our patients.

There were no obvious CBP therapy-related complications.

This case series has some limitations: a small number of patients of various ages and different pathologies. The clinical outcome in neurosurgical patients is often bound to the main disease. In this case series, three patients had terminal episodes due to underlying neurological and cardiac conditions; these explain the lack of statistically significant results at 48 and $72 \mathrm{~h}$. We used two different types of CRRT membranes.

\section{Conclusion}

The most important finding of the current case series describing patients admitted with primary brain injury who developed septic shock, is that we observed shock reversal in four patients within 2 days. We hypothesize that this was the result of complex intensive care, which included basic septic shock treatment and CBP therapy. Our results suggest that CBP therapy may have a role for septic shock patients after neurosurgical interventions, which should be tested in prospective randomized controlled trials in this specific population.

\section{Abbreviations}

AKI: Acute kidney injury; aPTT: Activated partial thromboplastin time; CBP: Combined blood purification; CRRT: Continuous renal replacement therapy; CPR: Cardio-pulmonary resuscitation; CVVHDF: Continuous veno-venous hemodiafiltration; DAMP: Damage-associated molecular pattern; DIC:
Disseminated intravascular coagulation; EAA: Endotoxin activity assay; GCS: Glasgow Coma Scale; MSSA: Methicillin-sensitive Staphylococcus aureus; MOF: Multiple organ failure; PAMP: Pathogen-associated molecular pattern; PE: Pulmonary embolism; SOFA: Sequential organ failure assessment score; KDIGO: Kidney Disease Improving Global Outcomes.

\section{Authors' contributions}

All authors contributed to the study conception and design. Data collection was performed by BA and KD. Data analysis was performed by BA, DG and SY. Material preparation was done by BA, AT, KN and SI. The first draft of the manuscript was written by BA and all authors commented on the manuscript. All authors read and approved the final manuscript.

\section{Funding}

The research was not funded any party.

\section{Availability of data and materials}

The data have been collected and stored according to the personal data and health information storage regulations and are available upon request to ensure the case report data transparency.

\section{Code availability}

Not applicable.

\section{Declarations}

Ethics approval and consent to participate

Not applicable.

\section{Consent for publication}

Not applicable.

\section{Competing interests}

The authors declare that they have no conflict of interest.

\section{Author details}

${ }^{1}$ Federal State Autonomous Institution N. N. Burdenko National Medical Research Center of Neurosurgery of the Ministry of Health of the Russian Federation, Moscow, Russian Federation. ${ }^{2}$ Federal State Budget Educational 
Institution of Higher Education M. V. Lomonosov Moscow State University, Moscow, Russian Federation.

Received: 28 December 2020 Accepted: 20 November 2021

Published online: 20 December 2021

\section{References}

1. Rhodes A, et al. Surviving sepsis campaign: international guidelines for management of sepsis and septic shock: 2016. Intensive Care Med. 2017:43(3):304-77.

2. Burkhart CS, Siegemund M, Steiner LA. Cerebral perfusion in sepsis. Crit Care. 2010;14(2):215.

3. Bellaver $B$, et al. Systemic inflammation as a driver of brain injury: the astrocyte as an emerging player. Mol Neurobiol. 2018;55(3):2685-95.

4. Dal-Pizzol F, Tomasi CD, Ritter C. Septic encephalopathy: does inflammation drive the brain crazy? Braz J Psychiatry. 2014;36(3):251-8.

5. De Vriese AS, et al. Cytokine removal during continuous hemofiltration in septic patients. J Am Soc Nephrol. 1999;10(4):846-53.

6. Trager K, et al. Treatment of post-cardiopulmonary bypass SIRS by hemoadsorption: a case series. Int J Artif Organs. 2016:39(3):141-6.

7. Brouwer WP, et al. Hemoadsorption with CytoSorb shows a decreased observed versus expected 28-day all-cause mortality in ICU patients with septic shock: a propensity-score-weighted retrospective study. Crit Care. 2019;23(1):317.

8. Matsumoto $\mathrm{H}$, et al. The clinical importance of a cytokine network in the acute phase of sepsis. Sci Rep. 2018;8(1):13995.

9. Poli EC, et al. Cytokine clearance with CytoSorb ${ }^{\circledR}$ during cardiac surgery: a pilot randomized controlled trial. Crit Care. 2019;23(1):108.

10. Gruda MC et al. Broad adsorption of sepsis-related PAMP and DAMP molecules, mycotoxins, and cytokines from whole blood using CytoSorb ${ }^{\circledR}$ sorbent porous polymer beads. PLoS ONE. 2018;13(1):e0191676.

11. Bonavia A, et al. Clinical utility of extracorporeal cytokine hemoadsorption therapy: a literature review. Blood Purif. 2018;46(4):337-49.

12. David $\mathrm{S}$, et al. Effect of extracorporeal cytokine removal on vascular barrier function in a septic shock patient. J Intensive Care. 2017;5:12.

13. Matsui T, et al. The effect of continuous renal replacement therapy with the AN69ST membrane on inflammatory markers and the level of consciousness of hemodialysis patients with stroke: comparison with hemodialysis with low blood flow rate. Prilozi. 2018;39(2-3):29.

14. Lees $\mathrm{NJ}$, et al. Combination of ECMO and cytokine adsorption therapy for severe sepsis with cardiogenic shock and ARDS due to Panton-Valentine leukocidin-positive Staphylococcus aureus pneumonia and H1N1. J Artif Organs. 2016;19(4):399-402.

15. Friesecke $\mathrm{S}$, et al. Extracorporeal cytokine elimination as rescue therapy in refractory septic shock: a prospective single-center study. J Artif Organs. 2017;20(3):252-9.

16. Friesecke $\mathrm{S}$, et al. International registry on the use of the CytoSorb(R) adsorber in ICU patients: study protocol and preliminary results. Med Klin Intensivmed Notfmed. 2019:114(8):699-707.

17. Hetz H, et al. Septic shock secondary to beta-hemolytic streptococcusinduced necrotizing fasciitis treated with a novel cytokine adsorption therapy. Int J Artif Organs. 2014;37(5):422-6.

18. Kobe $Y$, et al. Direct hemoperfusion with a cytokine-adsorbing device for the treatment of persistent or severe hypercytokinemia: a pilot study. Blood Purif. 2007:25(5-6):446-53.

19. Jain S, Sinha S, Sharma SK, Samantaray JC, Aggrawal P, Vikram NK, Biswas A, Sood S, Goel M, Das M, Vishnubhatla S, Khan N. Procalcitonin as a prognostic marker for sepsis: a prospective observational study. BMC Res Notes. 2014;17(7):458.

20. Hawchar F, et al. Extracorporeal cytokine adsorption in septic shock: A proof of concept randomized, controlled pilot study. J Crit Care. 2019:49:172-8

\section{Publisher's Note}

Springer Nature remains neutral with regard to jurisdictional claims in published maps and institutional affiliations.

Ready to submit your research? Choose BMC and benefit from:

- fast, convenient online submission

- thorough peer review by experienced researchers in your field

- rapid publication on acceptance

- support for research data, including large and complex data types

- gold Open Access which fosters wider collaboration and increased citations

- maximum visibility for your research: over $100 \mathrm{M}$ website views per year

At BMC, research is always in progress.

Learn more biomedcentral.com/submissions 